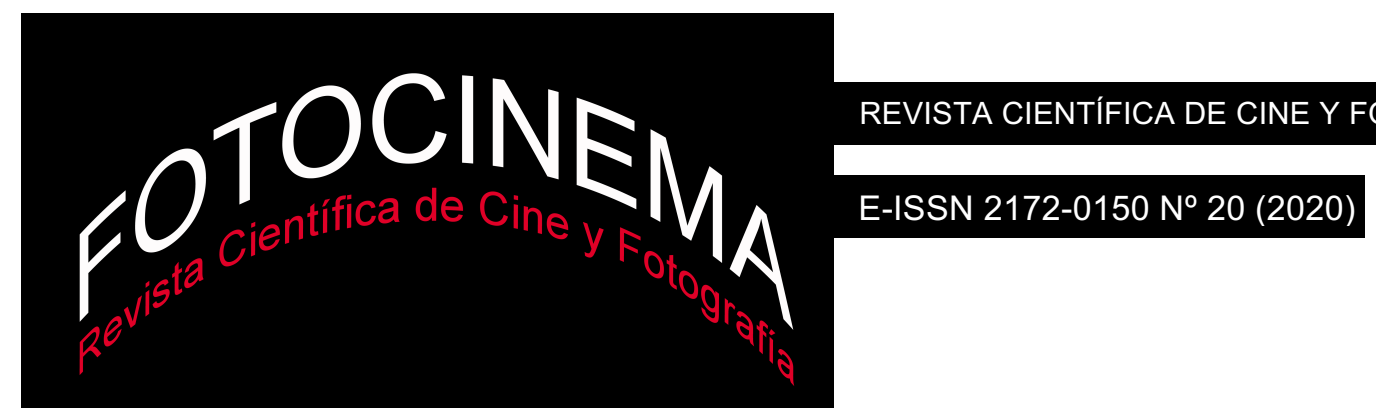

\title{
La propuesta audiovisual y el discurso del Museo de la Memoria y los Derechos Humanos de Santiago de Chile ${ }^{1}$
}

\section{The audiovisual proposal and the discourse of the Museum of Memory and Human Rights of Santiago de Chile}

\author{
Minerva Campos Rabadán \\ Universidad Autónoma de Madrid, España \\ minerva.campos@uam.es
}

\begin{abstract}
Resumen:
Este trabajo analiza los audiovisuales del Museo de la Memoria y los Derechos Humanos de Santiago de Chile, dado que constituyen el eje articulador de la colección permanente dedicada a las violaciones sistemáticas de los Derechos Humanos perpetradas en el país durante la dictadura pinochetista (1973-1990). La propuesta se ocupa también de presentar el museo en el contexto de las políticas de la memoria del país y de su voluntad de ampliar el discurso más allá de los límites de la colección permanente a través de actividades paralelas, exposiciones temporales y lo que hemos denominado el museo virtual.
\end{abstract}

\section{Abstract:}

This paper analyses the moving images belonged to The Museum of Memory and Human Rights of Santiago de Chile. In there, images suppose the axis of the permanent exhibition, devoted to the Human Rights violations committed by the Pinochet's dictatorship (1973-1990). The proposal also studies the museum within the memory policies developed by Chile and the effort of the institution in going beyond the strict limits of its main collection by the organization of parallel activities, temporal exhibitions and what we have called the virtual museum.

Palabras clave: museografía audiovisual; memoria; dictadura chilena; testimonios; documental.

Keywords: Audiovisual Museography; Memory; Chilean Dictatorship; Testimonies; Documentary.

\footnotetext{
${ }^{1}$ Agradecemos al equipo del Museo de la Memoria la buena disposición, el trato y las facilidades para realizar el trabajo de campo; de manera especial a María Luisa Ortiz, por su atención y su confianza. Este trabajo ha recibido el apoyo del Programa Permanente de Movilidad para Personal Docente e Investigador a través de Convenios Internacionales de la Universidad Autónoma de Madrid.
} 
Las políticas de la memoria y las iniciativas de colectivos y agrupaciones han tejido en las últimas décadas en Chile una red de sitios de memoria y espacios para la reflexión que es cada año más extensa. Entre todos ellos, inaugurado en 2010, el Museo de la Memoria y los Derechos Humanos de Santiago es la punta de lanza de las políticas de la memoria puestas en marcha por el Estado con respecto a la dictadura militar del periodo 19731990. En este sentido, frente a la relativa independencia de otras iniciativas y las particularidades de los relatos que cada una articula, no cabe duda del carácter oficial y la voluntad conciliadora del Museo de la Memoria².

El objeto central de este artículo son las imágenes en movimiento del museo, tan protagonistas que marcan también una diferencia radical con respecto a otros sitios de memoria emblemáticos de Santiago. Como veremos, no se trata solo de la importancia que tienen estos materiales en la exposición, sino también del esfuerzo de la institución por producir nuevas imágenes que incorporar a la memoria colectiva sobre la dictadura.

\section{El proyecto de museo}

Inaugurado bajo la presidencia de Michelle Bachelet el 11 de enero de 2010, el museo se presenta como uno de los grandes proyectos del Bicentenario y como una iniciativa de la Presidencia ${ }^{3}$. Situado en el barrio Yungay, nace como un espacio desde el que proponer y trabajar una memoria colectiva.

\footnotetext{
2 Aunque la fórmula jurídica de dicha institución es la de un Instituto de Derecho Privado, su financiación es pública. La voluntad política de asegurar la independencia del museo fue lo que llevó a esta fórmula para su gestión. Entrevista de la autora con María Luisa Ortiz. Jefa del área de Colecciones e investigación. Museo de la Memoria y los Derechos Humanos. Santiago de Chile. 23 de julio de 2019. El ente gestor surge de la confluencia en la Fundación Colecciones de la Memoria, de representantes de la presidencia de la nación y de la corporación Casa de la Memoria, conformada por organismos por la defensa de los Derechos Humanos: la Fundación de Ayuda Social de las Iglesias Cristianas (FASIC), la Corporación de Promoción y Defensa de los Derechos del Pueblo (CODEPU), la Fundación de Protección de la Infancia Dañada por los Estados de Emergencia (PIDEE) y Teleanálisis (MMDDHH, 2019a).

3 Se encomendó la tarea a la Comisión Presidencial de Derechos Humanos, que articuló un grupo de trabajo en el que participaban la Comisión misma, el Ministerio de Obras Públicas, la Dirección de Archivos y Museos y el Ministerio de Bienes Nacionales (Serrano Madrid, 2010, p. 18).
} 
Además de la colección permanente y las exposiciones temporales, el museo organiza multitud de actividades paralelas como seminarios, presentaciones y proyecciones que invitan a la participación de los ciudadanos en el proyecto de diálogo. Del mismo modo, el museo acoge otras actividades externas relacionadas con la memoria, la historia o los Derechos Humanos, instituyéndose como epicentro no solo de la memoria colectiva sobre la dictadura chilena, sino también de los debates en torno a la misma.

El diseño del Museo de la Memoria es obra del Estudio América4, adjudicatario del proyecto en el concurso público convocado en 2007. El museo cuenta con un edificio principal que alberga la colección permanente y que está situado en una explanada que tiene por nombre Plaza de la Memoria y desde la que se accede también al auditorio y al espacio subterráneo donde puede verse la instalación de Alfredo Jaar "La geometría de la conciencia". La colección permanente ocupa las plantas uno y dos del edificio principal que, en su planta baja, ofrece una panorámica sobre casos de violación de Derechos Humanos y comisiones de verdad en el mundo, así como una introducción a los espacios de memoria en Chile. El edificio principal también acoge el Centro de Documentación (CEDOC, en el sótano) y, en su tercera planta, el Centro de Documentación Audiovisual (CEDAV) y un espacio para exposiciones temporales. Las tres plantas centrales del edificio principal están conectadas por una galería que queda abierta en uno de los laterales y en cuya pared, visible desde los diferentes pisos, preside el museo un mosaico con rostros de asesinados y desaparecidos por la dictadura de Pinochet. La apertura de los espacios permite también la entrada de luz natural a través de la fachada de cristal del edificio, así como el recorrido libre de los visitantes y, como veremos, de los sonidos.

Con respecto a la exposición, el museo tiene un discurso temporal muy estricto: su colección permanente considera desde el bombardeo al Palacio de la Moneda el 11 de septiembre de 1973 hasta el 11 de marzo de 1990, fecha de la toma de posesión del Presidente Patricio Aylwin. Sin embargo, tanto los

\footnotetext{
4 Integraban el Estudio América Carlos Dantas Días, Lucas Fehr y Diego Figueroa, a quienes se asoció el arquitecto chileno Roberto Ibieta. Sobre el proyecto arquitectónico ver Museo de la Memoria y los Derechos Humanos, 2010.
} 
materiales disponibles en el CEDOC, como las actividades paralelas acogidas por la institución y las exposiciones temporales, amplían estos marcados límites5. Esta restricción temporal es uno de los motivos por los que el museo es objeto de continuos debates más o menos públicos. Algo que ocurre también con respecto a las víctimas consideradas como tales por la institución, que se acoge a los resultados de la Comisión de Verdad y Reconciliación (1990) recogidos en el Informe Rettig (1991). Sobre esta discusión señala Elizabeth Lira:

[...] en Chile hay víctimas de distintos sectores de la sociedad y en los distintos bandos del conflicto. [...] La Comisión de la Verdad y Reconciliación reconoció a estas víctimas [las que perdieron la vida en acciones armadas realizadas por opositores a la dictadura] y las incluyó como beneficiarias de las políticas de reparación, pero puede observarse una cierta resistencia de distintos sectores. [...] Tal vez esa resistencia da cuenta de las dificultades del actual proceso de reconciliación política, que se ha sostenido sobre el reconocimiento de los derechos de todas las víctimas (2009, p. 72).

Es una discusión que se ha mantenido después de la inauguración del museo. En cualquier caso, posiblemente sea la voluntad conciliadora de la institución lo que la anima a seguir los criterios externos (y oficiales) señalados.

Aunque ajustados a su espectro temporal, la colección permanente cuenta con materiales diversos. Dispuestos en salas cuyos títulos sirven para organizarlos temática y cronológicamente, los encontramos en espacios como la "Sala 11 de septiembre", que inaugura el recorrido, "Fin del Estado de derecho", "Una nueva institucionalidad", "Condena internacional", "La dictadura traspasa las fronteras", "Represión y tortura", "Dolor de los niños" o "Artesanía carcelaria" (todas en la primera planta) y otras como "Demanda de verdad y justicia", "Ausencia y memoria", "Lucha por la libertad", "Retorno a la esperanza y fin de la dictadura" (segunda planta). Se observa también aquí una nomenclatura de tono administrativo y conforme a la terminología empleada por las comisiones de verdad y las políticas de memoria.

5 Podemos entender que opera en la misma dirección la retransmisión en tiempo real de imágenes de la fachada del Palacio de la Moneda que encontramos en la "Sala 11 de septiembre". 
A pesar de su organización espacial, las salas son abiertas y los visitantes pueden diseñar su propio recorrido. En todas, los materiales se complementan: audiovisuales, objetos, mapas, paneles explicativos, estaciones multimedia, documentos y publicaciones de cada uno de los episodios y los periodos en los que se articula la exposición. Entre los objetos $^{6}$, destacan algunos como las arpilleras, dibujos y artesanías realizadas por las víctimas durante su cautiverio, una bandera presidencial que debió ondear en La Moneda hasta mediados de los años 1960 y que fue rescatada después del bombardeo ${ }^{7}$ y la carta de una niña de nueve años a Lucía Hiriart solicitando información sobre sus abuelos "que fueron sacados un día dos de abril" (primera planta).

Sin embargo, consideramos que el elemento protagonista en el discurso del museo es el audiovisual. Las imágenes y registros de la colección son numerosos y diversos, como lo son las pantallas que los ponen a disposición de los y las visitantes en los espacios físicos y virtuales del museo ${ }^{8}$. En este sentido, el museo surge en clara sintonía con las líneas maestras de la llamada nueva museografía que, desde la década de 1980, tiende a reducir la presencia de especímenes y piezas en los espacios expositivos en favor de informaciones y materiales complementarios que, con frecuencia, se apoyan en las nuevas tecnologías y tecnologías digitales (Alonso Fernández, 1999; Iáñez Ortega, 2014, p. 45).

En todos los casos, las imágenes han sido incorporadas al museo gracias donaciones de particulares y profesionales. Cada uno de los materiales tiene un acuerdo específico de cesión al museo que se compromete, en todo caso, a salvaguardarlos y a contribuir a su difusión a través de sus espacios y actividades9: incorporándolos a la colección permanente, al catálogo del CEDOC y el CEDAV y exhibiéndolos en colaboración con otras instituciones

\footnotetext{
${ }^{6}$ En ellos se detiene en su trabajo sobre el Museo Tatiana Wolff Rojas (2017).

7 La bandera se incorporó a la exposición en 2019 de manera temporal dadas las condiciones de conservación que requiere.

8 En un trabajo anterior, planteamos también las dimensiones del museo más allá de lo físico en relación con su museografía audiovisual (Campos, 2017).

9 Entrevista de la autora a María Luisa Ortiz. Jefa del área de Colecciones e investigación. Museo de la Memoria y los Derechos Humanos. Santiago de Chile. 23 de julio de 2019.
} 
o en su programa regular de proyecciones en el auditorio / sala de cine del museo.

Debido a decisiones que tienen que ver con la exposición, pero también con los derechos que el museo detenta, el acceso a los audiovisuales varía de un caso a otro. Igualmente, la puesta a disposición de los visitantes de algunos materiales está condicionada por la capacidad del archivo (online y local) y el ritmo al que el CEDOC sube materiales al repositorio. De cara a la aproximación que haremos a los audiovisuales, conviene tener presente que todos los materiales forman parte del catálogo del CEDOC; además, muchos están disponibles en los terminales del CEDAV instalados en la tercera planta del museo, pero solo algunos de ellos lo están también en el museo virtual (en la biblioteca digital y la página web del museo).

Destaca, en todo caso, la facilidad de acceso y consulta a estos materiales en el museo, tanto en el CEDOC, que cuenta con una biblioteca de acceso abierto y ordenadores de mesa para consulta y trabajo, como en el CEDAV. En este último, el visitante puede pedir prestados auriculares para la consulta de materiales audiovisuales tanto en las pantallas de mayor tamaño instaladas en pequeñas salas de visionado abiertas, de acuerdo con la línea de diseño del museo, como en los puestos informáticos situados al lado.

\section{Estudios y sitios de memoria: un marco para el caso propuesto}

Como certeramente ha expuesto Elizabeth Jelin, "[1]a lucha por el sentido del pasado se da en función de la lucha política presente" (2005) y, en el contexto que nos ocupa, tiene que ver también con la política en su sentido más administrativo, dado que el proyecto del Museo de la Memoria parte como propuesta de la Presidencia y cuenta con financiación pública.

Con respecto a este museo, y a otros sitios de memoria, estaríamos hablando de la concreción material de lo que Jelin denominó "espacios sociales de circulación de la memoria" e identificó como "mecanismos necesarios para la elaboración de las experiencias traumáticas" (Jelin, 2005) ${ }^{10}$. Se trata de un

10 En esta misma línea, también Andreas Huyssen entiende los museos, los memoriales y los 
espacio que, en este caso, es altamente institucional y se presenta como emblema de las políticas de la memoria en Chile. En esta tarea de poner en circulación memorias y experiencias, destaca la importancia que el registro, archivo y difusión de testimonios tienen para el Museo de la Memoria, así como la búsqueda activa que llevan a cabo sus equipos de documentación y audiovisuales para incorporar nuevos relatos al archivo del museo y, así, a la memoria colectiva que propone. Por ello, reconocemos en el museo un fomento de la "reinterpretación y la resignificación del sentido de las experiencias transmitidas por 'otros' a los que se quiere incorporar" a esa memoria colectiva a través de estas operaciones de registro y difusión de testimonios, podemos añadir (Jelin, 2005).

Junto con la memoria, el segundo objeto del museo son los Derechos Humanos. Consideramos que, por un lado, contribuyen a instalar el discurso sobre la dictadura chilena en un contexto más amplio, pero también a flexibilizar los estrictos límites temporales a los que está sometida su colección permanente. En uno de sus trabajos, Andreas Huyssen atiende de manera específica a los estrechos vínculos entre Derechos Humanos y memoria y al modo en que colaboran entre ellos. Señala que los estudios contemporáneos sobre la memoria deberían estrechar sus lazos con los Derechos Humanos y la justicia para evitar que la memoria, especialmente la memoria traumática, apunta, se encierre en sí misma; por otro lado, identifica también el peligro que corre el discurso sobre los Derechos Humanos de perder su conexión histórica y convertirse en algo abstracto (Huyssen, 2011, p. 608).

Por su parte, Jelin señala la estrecha asociación que en Argentina existe entre los Derechos Humanos y la dictadura y se pregunta si esta traducción podría estar limitando o impidiendo una concepción más amplia de estos (Jelin, 2014, pp. 233-234). Es posible que con la voluntad de disociar las particularidades de la dictadura de los Derechos Humanos en un sentido más extenso, el Museo de la Memoria reservara en su proyecto museográfico un espacio para exposiciones temporales que permitieran ampliar el discurso de las sociedades modernas (Huyssen, 2002, pp. 146-147). 
la colección permanente. Así, las exposiciones que tienen lugar en la tercera planta del museo aluden a diferentes artículos de la Declaración Universal de los Derechos Humanos; y este suele ser también el caso de las exposiciones organizadas al aire libre, en la Plaza de la Memoria'11. Junto con completar la propuesta museográfica, estas exposiciones contribuirían a una experimentación entre sucesos diversos que evitara la "objetivación" y "cristalización" de memorias y recuerdos que teme Nelly Richard (2002, 191). En este sentido, las exposiciones temporales invitarían a mirar los Derechos Humanos como algo más amplio que lo estrictamente relacionado con la dictadura chilena, pero también a la reactualización de la dictadura a partir de las perspectivas sobre Derechos Humanos propuestas desde otros temas y problemáticas muchas veces contemporáneas.

Por otro lado, poniendo en relación la naturaleza de los diferentes elementos dispuestos en la colección permanente del museo, Huyssen apunta que "[u]na de las razones para la nueva fuerza del museo y del monumento en el espacio público acaso tenga que ver con el hecho de que ambos brindan lo que la televisión e internet deniegan: la calidad material del objeto" y su "permanencia" en la que sería "una cultura híbrida de los memoriales y los medios" (Huyssen, 2002, p. 155). Creemos que es precisamente de este modo como debemos pensar el diseño y el discurso del Museo de la Memoria, con una fuerte atención a los objetos, vestigios materiales de la dictadura y propiedad de quienes fueron sus víctimas o sus victimarios, decididamente presentes en la exposición, pero con la vocación de trascender el espacio físico de sus paredes a través de un amplio diseño en lo que llamamos el museo virtual, constituido por los materiales digitalizados y el amplio catálogo audiovisual disponible en sus centros de documentación y, también parcialmente, en Internet.

\footnotetext{
${ }^{11}$ Entre julio y agosto de 2019 el museo acogió exposiciones de carácter artístico y didáctico: "Obras de Graciela Sacco: ¿Quién fue? - Ojos y T4" (19/01/2019-04/08/2019, Explanada Sala audiovisual), "Los invisibles. Ingrid Wildi Merino (09/08/2019-20/10/2019, Sala audiovisual), "Nosotros y los Otros. De los prejuicios al racismo" (25/04/2019-27/09/2019, Sala de exposiciones temporales) e "Impulsar la justicia social, promover el trabajo decente. 100 años de la OIT" (12/06/2019-10/11/2019, Hall CEDOC).
} 
La potencia del discurso del Museo de la Memoria se construye, sin embargo, sobre sus audiovisuales: con los materiales expuestos, pero más radicalmente con las piezas que el museo ha producido desde 2010. En los estudios de la memoria se ha abordado, por un lado, la necesidad de desacralizar el testimonio en primera persona a pesar de reconocer su valor documental ${ }^{12}$, pero también la de "crear imágenes del terror" que den cuenta de los horrores de la dictadura y es, precisamente en esta intersección, donde podemos situar los audiovisuales producidos por el Museo de la Memoria. Es Huyssen quien señala la necesidad de esas "imágenes del terror" posteriores a los hechos y en cualquier formato considerando la "ausencia de imágenes documentales que provengan de los propios campos y centros de detención", en Argentina en el caso que él expone (Huyssen, 2009, pp. 15-24). Este parece ser uno de los retos que asume el Museo de la Memoria y al que responde con un registro continuado de testimonios que archiva en el CEDOC $^{13}$. Se pone en este caso de manifiesto lo que apunta Beatriz Sarlo, también con respecto al caso argentino, sobre cómo estos testimonios se constituyen necesariamente como "el núcleo de un saber sobre la represión" hasta que aparezcan otros documentos de momento inexistentes, como las imágenes a las que se refiere Huyssen (Sarlo, 2005, p. 61).

Por último, si, como establece Elizabeth Jelin, la memoria colectiva es el resultado de múltiples memorias más particulares en disputa ${ }^{14}$, el caso chileno y su relación con la dictadura que padeció entre 1973 y 1990 es un claro ejemplo de tal polifonía de voces. Si bien hay un proyecto de patrimonialización oficial que reconoce como tales los sitios de memoria distribuidos por el país, lo cierto es que la mayoría de espacios han surgido como iniciativa de agrupaciones y colectivos más o menos extensos que ahora los gestionan y que operan de manera relativamente independiente (entre

\footnotetext{
12 Ver Sarlo, 2005, 84.

13 También encontramos algunos fragmentos de estos registros en la colección permanente y el museo virtual dado que se elaboran piezas más breves, a veces de carácter temático, combinando varios testimonios con el propósito de resultar más atractivos y sintéticos para el visitante.

14 Ver Jelin, 2002, 6. En esta línea, también señala la autora las "contradicciones, tensiones, silencios, conflictos, huecos, disyunciones, así como lugares de encuentro y aún 'integración'" entre las "memorias individuales" y "las públicas" (Jelin, 2002 [2001], 32).
} 
ellas y en relación al Estado, aunque hay un interés compartido por visibilizar todos estos lugares).

En varios trabajos, Carolina Aguilera ha cartografiado los monumentos y sitios de memoria de la Región Metropolitana de Santiago entre los que se integra el Museo de la Memoria (Aguilera, 2013; 2015; Aguilera y Cáceres, 2012). Como decíamos, son diferentes las entidades y agrupaciones responsables de cada uno de ellos, y encontramos grandes diferencias en la gestión, el acceso, la comunicación, la señalización e incluso en el tipo de visita posible de lugares como la Clínica Santa Lucía, Londres 38, Parque de la Paz Villa Grimaldi, el Estadio Nacional o el Patio 29 del Cementerio General15. El diálogo tenso entre el Museo de la Memoria como dueño del relato considerado oficial y otros sitios, apoyados por el Estado a través de sus políticas de Derechos Humanos y patrimonio, pondría de manifiesto el poder del Estado como agente articulador de la memoria colectiva. Es también este otro de los puntos álgidos en los debates de los que es objeto el Museo de la Memoria, siendo considerado el espacio para la memoria privilegiado por el Estado que, en este marco particular, "[a] través de su reconocimiento formal o simbólico, jerarquiza ciertas voces y silencia otras", o les baja el volumen, podemos añadir (Jelin, 2009, p. 125).

Cabe también mencionar cómo algunos de los sitios, a pesar de recibir algún tipo de reconocimiento o subsidio por parte del Estado, insisten en su independencia en su interacción con los visitantes, lo cual, junto con las diferencias significativas ya señaladas, dificulta la identificación de características que den cuenta de la verdadera independencia u oficialidad de cada uno de estos sitios.

En todo caso, también en el nivel de su discurso memorístico y el diseño de su exposición existen vínculos estrechos entre el Museo de la Memoria y algunos de los sitios referidos. Podemos señalar, como ejemplo más significativo, la cruz del Patio 29 del Cementerio General que está expuesta

15 Casi todos estos lugares forman parte de la Ruta de la Memoria. Ver Ministerio de Bienes Nacionales, 2015. Carolina Aguilera ha trabajado también en particular sobre Londres 38 y el Patio 29 (Aguilera, 2013). 
en la planta baja del museo, habiendo sido sustituida en su lugar de origen por una placa que señala su reubicación.

\section{El protagonismo del audiovisual en la colección permanente}

Dispuestos en las diferentes galerías y plantas que ocupa la colección permanente del Museo de la Memoria, encontramos monitores, estaciones multimedia y alguna proyección. Destacan, por la centralidad y potencia de las imágenes, dos salas: la dedicada al golpe y titulada "11 de septiembre" y los espacios dedicados a las diferentes fases del plebiscito, en los que se muestra desde las campañas de propaganda electoral del SÍ y del NO hasta testimonios de algunos protagonistas del momento, reportajes dedicados al proceso de votación y registros de las celebraciones tras los resultados.

La instalación de tres pantallas que inaugura la visita en la sala dedicada al 11 de septiembre de 1973 se constituye como el centro del discurso audiovisual. En el diseño general del museo podemos decir que comparte protagonismo con el mosaico de los rostros de asesinados y desaparecidos de la pared visible desde todas las plantas del edificio. La importancia de la sala viene dada por el espacio que ocupa y el tamaño de los tres monitores que muestran un montaje audiovisual en el que destacan las imágenes del bombardeo al Palacio de la Moneda, pero también porque el sonido de los bombardeos e, igualmente identificable, el de las últimas palabras del Presidente Salvador Allende a través de Radio Magallanes, ocupa todo el espacio del museo: siendo audible para el visitante antes de llegar a la sala y acompañándolo durante todo su recorrido. De esta manera, dicha banda de sonido se incorpora también a otras imágenes que se reproducen en bucle o que se activan con la interacción del visitante en las demás salas. Los registros de cámara, que muestran imágenes del Palacio de la Moneda, el bombardeo al que fue sometido y los altercados que se sucedieron en las inmediaciones, son de procedencia diversa ${ }^{16}$, aunque el origen de los

${ }^{16}$ Materiales de Chilefilms; de los registros del bombardeo a la Moneda de Pedro Chaskel, de los días 11, 13 y 14 de septiembre del camarógrafo Juan Ángel Torti, de Jorge Vargas para TVN, y de Claudio Sánchez para Canal 13; del documental Más fuerte que el fuego (Walter Heinowski y Gerhard Scheumann, 1978); de La Spirale (Armand Mattelart, Jacqueline 
materiales no se indica. Como decíamos, la locución y el sonido de dicho montaje, que muestra de manera cronológica los acontecimientos citados, acompañan al visitante durante todo su recorrido, llegando a cada uno de los rincones de la colección permanente ${ }^{17}$.

Esta "Sala 11 de septiembre" tiene un carácter eminentemente audiovisual ${ }^{18}$. En uno de los laterales de la triple pantalla descrita, se encuentra otra de gran formato (compuesta por cuatro monitores) en la que se emite en directo la imagen de la fachada principal del Palacio de la Moneda, con el claro propósito de acercar espacial y temporalmente los acontecimientos que se muestran en las pantallas más próximas y la violación sistemática de los Derechos Humanos cometida durante casi dos décadas, cuyo relato (uno de los muchos que circulan) conocerá el visitante a lo largo de su recorrido. Completan esta primera sala seis monitores con auriculares instalados en cubos blancos, cuyas pantallas apuntan hacia el techo y a los que el visitante puede asomarse para detenerse en episodios concretos de ese mismo día. Así, los diferentes cubos - "Testimonios", "Registro documental del periodista Jaime Vargas", "Registro radial de las últimas palabras del Presidente Salvador Allende", "Detenciones masivas en todo el país", "Población de Chile" y "Primera cadena nacional de la Junta Militar" — nos devuelven a septiembre de 1973 y a sus imágenes y sonidos ${ }^{19}$.

Por su parte, el área dedicada al plebiscito del 5 de octubre de 1988 se encuentra articulada en varias salas organizadas de manera cronológica. En un primer espacio se encuentran los materiales audiovisuales relativos a los días previos a la votación que, podemos decir, rompen el tono solemne y trágico del museo para abrazar una museografía, si se quiere, de estilo pop:

Meppiel y Valerie Mayoux, 1976); del reportaje "11 de septiembre", de Chilevisión; y algunas otras imágenes de la Televisión Alemana ZDF.

${ }_{17} \mathrm{Si}$ bien desde el Museo señalan lo no pretendido de este diseño sonoro, lo cierto es que resulta clave en la experiencia de visitar la colección permanente. Entrevista de la autora con José Manuel Rodríguez Leal. Responsable del archivo audiovisual del Museo de la Memoria y los Derechos Humanos. Santiago de Chile. 13 de agosto de 2019.

${ }^{18}$ Casi todos los audiovisuales se encuentran dispuestos en pantallas, tanto las piezas mono y multicanal que se reproducen en bucle, como las estaciones multimedia. Solo las imágenes de la noche del plebiscito y una representación (presente) sintética y a contraluz de ciudadanos votando se encuentran proyectadas en dos de las paredes del segundo piso.

19 Tampoco en estos casos aparecen en la exposición los créditos de los registros audiovisuales. 
testimonios en una pantalla localizada en una de las paredes y, frente a ella, otra en la que se puede ver el ambiente en la calle y la expectación en esos días así como la atracción central del espacio, un aparato de televisión de la época (cuya pantalla catódica ha sido sustituida por una digital) frente a la que el visitante puede sentarse en un banco y someterse a fragmentos de las campañas televisivas creadas para defender las opciones del SÍ y del NO. Es en este punto donde el museo se torna pop, como decimos, con el atrezzo, pero también por influencia de las canciones y sintonías de las diferentes cuñas de propaganda electoral emitidas en 1988 y los temas musicales compuestos para animar a votar por cada una de las dos opciones, -así como con el merchandising diseñado con el mismo propósito que el visitante puede conocer al abrir las cajoneras que se encuentran junto al aparato de televisión-. La visita, sin embargo, regresa a un tono más informativo y solemne en las salas siguientes para documentar el resultado del plebiscito y los pasos en el proceso hacia la democracia.

Junto con estas imágenes que el museo ofrece en un marco específico y muy consciente, a lo largo del recorrido hay numerosas estaciones multimedia apoyando las informaciones que mediante documentos, objetos, imágenes fijas y textos escritos articulan el tema que se presenta en cada una de las galerías y salas. Encontramos monitores multimedia en los que realizar búsquedas y consultas: de las políticas de reconocimiento y reposición de las víctimas que ha implantado el gobierno chileno desde 1990, hasta búsquedas sobre las víctimas consideradas como tales por las Comisiones de Verdad en Chile ${ }^{20}$.

Resultan más pertinentes en nuestra aproximación los multimedia que permiten navegar por materiales audiovisuales organizados temáticamente y en diálogo con los demás objetos y materiales de las salas en las que se ubican. Hay tres estaciones de este tipo: en las salas "Fin del Estado de

20 Es posible consultar el archivo de víctimas también desde la web del Museo (ver https://interactivos.museodelamemoria.cl/victimas/). Otros de los multimedia con texto e imágenes estáticas que se encuentran en la exposición están dedicados a Memoriales y Recintos e igualmente están disponibles en el museo virtual. Ver https://interactivos.museodelamemoria.cl/memoriales/_y y http://interactivos.museodelamemoria.cl/recintos/. 
derecho" y "Represión y tortura", ambas en el primer piso, y en la de "Lucha por la libertad", en el segundo. En todos los casos, el visitante tiene que activar la reproducción y las estaciones cuentan con un banco y altavoces, lo que permite la consulta atenta de los materiales al tiempo que la incorporación de más personas al visionado ya en curso. Las estaciones ofrecen desde videos de Teleanálisis a registros de procedencias diversas y fragmentos de documentales y reportajes de televisiones y cineastas extranjeros, que juntos suponen una de las bases del fondo y el discurso audiovisuales del museo ${ }^{21}$. En algunos casos, además, cada pieza pone en diálogo varios de estos materiales, como ocurre en la entrada "Base Naval de Talcahuano / Base El Morro de Talcahuano"22 y el video correspondiente, titulado "Campamento de prisioneros Isla Dawson: Región de Magallanes y la Antártica Chilena", que incluye fragmentos de los documentales de Walter Heynowski y Gerhard Scheumann La Guerra de los Momios (1974) y Los muertos no callan (1978). Entre las piezas que el visitante puede reproducir en el segundo de los multimedia citados, se encuentra un fragmento de Chile bajo la junta militar, de K. Eckstein para la televisión alemana (ZDF, Canal 2, 1973), que recoge imágenes de las quemas de libros en la vía pública que llevaron a cabo los militares, un video sobre el que volveremos.

\section{La producción audiovisual del museo}

Para ocuparnos de la producción propia hemos considerado tanto las grabaciones originales llevadas a cabo por el equipo del museo como las piezas elaboradas a partir de materiales de archivo ${ }^{23}$. Abordaremos diferentes ejemplos, cada uno de los cuales permite analizar, por un lado, la

${ }^{21}$ Sobre Teleanálisis ver Lagos, 2017, p. 145. Sobre películas y reportajes extranjeros en el periodo 1973 - 2013 ver Marcy Campos Pérez, 2015.

${ }^{22}$ Perteneciente a la estación multimedia de la sala "Fin del Estado de derecho" del primer piso del museo.

${ }^{23}$ Las diferentes piezas audiovisuales que están presentes en el museo (físico y virtual) han sido producidas por el equipo de audiovisuales desde su creación en 2009, aunque en este tiempo ha habido cambios con respecto al equipo original. Entrevista de la autora con José Manuel Rodríguez Leal. Responsable del archivo audiovisual del Museo de la Memoria y los Derechos Humanos. Santiago de Chile. 13 de agosto de 2019. José Manuel Rodríguez está en el proyecto desde 2009 y ha participado, con diferentes roles, en los audiovisuales producidos por el museo. 
propia pieza y, por otro, la manera en que se integra y se relaciona con el museo y sus diferentes espacios. Salvo excepciones, todas las producciones están disponibles en el CEDOV y casi todas en el CEDAV; sin embargo, en la mayoría de los casos solo encontramos breves fragmentos ilustrativos de algunas piezas en el museo virtual.

\subsection{El trabajo con el fondo audiovisual}

Junto con las imágenes expuestas como parte de la colección permanente relativas al bombardeo al Palacio de la Moneda y al plebiscito de 1988 que abordamos más arriba, destaca la pieza El dolor de los niños, por sus 60 minutos de duración y, sobre todo, por la diversidad de miradas, tiempos y materiales que le dan forma ${ }^{24}$. En este caso, la pieza se ubica en la sala del mismo nombre, que alberga imágenes y detalles de cartas y dibujos relacionadas con quienes eran niños durante el proceso y sufrieron la violencia del golpe y la dictadura en su propia persona o a través de las torturas, exilios o desapariciones forzadas a las que fueron sometidos sus padres y madres. En este caso, la pieza solo está disponible para el visitante en esta sala, donde deberá verla de pie frente al monitor donde se reproduce en bucle.

El dolor de los niños busca subrayar a los niños como víctimas de la dictadura y no presenta una progresión narrativa que vaya más lejos de la sucesión de fragmentos de los diferentes documentales y reportajes de donde provienen las imágenes de la pieza. Su organización tampoco es cronológica, por lo que los testimonios de niños y adolescentes se mezclan con los de víctimas ya adultas en el momento de la filmación, como ocurre en algunas de las películas más recientes en las que los protagonistas del testimonio son ya adultos y recuperan ellos mismos imágenes de archivo del tiempo de la dictadura, caso de Guerrero (Sebastián Moreno, 2017) y El edificio de los chilenos (Macarena Aguiló, 2010). Los materiales de la pieza pertenecen a documentales y reportajes producidos entre 1979 y 2017, por orden de

24 "El dolor de los niños" da cuenta también del esfuerzo del museo por comunicar adecuada y masivamente sus contenidos, habiendo incorporado el lenguaje de signos a este video haciéndolo accesible a partir de la interpretación de los testimonios y diálogos que se suceden en cada uno de los fragmentos de la pieza. Es interesante apuntar también que la pieza va incorporando nuevos materiales en cada actualización. 
montaje: Eran unos que venían de Chile (Claudio Sapiaín, 1986)²5, Colonias urbanas. El derecho a la sonrisa (Teleanálisis, 1984) ${ }^{26}$, Piececitos de niños (Colectivo América, 1986)27, Navidad en las poblaciones. El otro Viejo Pascuero (Teleanálisis, 1986) ${ }^{28}$, Javiera de Chile (Teleanálisis, 1989) ${ }^{29}$, Los huérfanos del Cóndor (Emilio Pacull, 2003)30, Guerrero, Los ojos como mi papá (Pedro Chaskel, 1979), Mi hermano y yo (Sergio Gándara, 2002), Los niños prohibidos (ICTUS, 1986) ${ }^{31}$ y El edificio de los chilenos.

Si bien la pieza se ocupa del modo en que la violencia de la dictadura y las políticas del gobierno militar afectaron a la infancia en Chile, el discurso militante y político se presenta también vinculado al exilio, la tortura, la desaparición forzada de personas y las condiciones habitacionales y económicas que urgían en el contexto chileno contemporáneo.

El dolor de los niños también subraya el carácter ideológico de la militancia de los padres, que se muestra en algunos casos como heredada por los hijos. Los ejemplos más claros se encuentran en los fragmentos de Guerrero, Los ojos como mi papá y en la escena de El edificio de los chilenos en que la madre de Macarena Aguiló lee una de las cartas que envió a su hija en el tiempo en que estuvieron separadas. En la segunda, Los ojos como mi papá, el discurso político de los niños y niñas se articula en forma de respuestas a entrevistas individuales y como comentarios en grupos más amplios. Como señalan José Miguel Palacios y Catalina Donoso, Los ojos como mi papá

funciona en clave dialéctica: por un lado, bajo una pulsión de transparencia y cesión de control frente al discurso de los niños, por otro, bajo una pulsión de instrumentalización de la celebración de la subjetividad infantil, al hacerla funcional a un discurso político mayor (Palacios y Donoso, 2017, pp. 56-57).

\footnotetext{
25 Documental para la televisión sueca. Sveriges Television SVT 1 (45 minutos).

${ }^{26}$ Reportaje de Augusto Góngora incluido en la entrega de Teleanálisis del 3 de octubre de 1984 (13 minutos).

27 Documental, dirigido por Hernán Fliman, pertenece a la serie de investigación Efectos de la tortura en Chile. Comisión Nacional Contra la Tortura (17 minutos).

${ }^{28}$ Reportaje de Augusto Góngora incluido en la entrega de Teleanálisis del 23 de diciembre de 1986 (9 minutos).

29 Reportaje de Augusto Góngora incluido en la entrega de Teleanálisis de marzo de 1989 (24 minutos).

$3^{30}$ Reportaje. Producción de Cauri Films con la participación de France 2.

${ }^{31}$ Documental de Augusto Góngora para ICTUS (26 minutos).
} 
También en Guerrero, el protagonista, en unas imágenes de archivo que lo muestran en un programa de televisión tras el asesinato de su padre, declara: "Ni las balas ni la represión, ni la intervención norteamericana en Chile van a detener la lucha del pueblo. Esto no va a cesar hasta botar la dictadura". Como se ve, el discurso político y de lucha es manifiesto en las intervenciones de los protagonistas. Sin embargo, los fragmentos seleccionados para la pieza pierden en parte la fuerza y los matices que tienen los reportajes y documentales originales, algunos de ellos títulos clave para pensar la dictadura chilena.

\subsection{Los testimoniantes y el espacio físico del museo}

El eje de todas estas producciones es el testimonio en presente de testigos, supervivientes y familiares de las víctimas y desaparecidos por la dictadura. Sin embargo, muchas de las piezas incluyen material de archivo de carácter ilustrativo, entre el que destaca el uso recurrente de las imágenes del bombardeo al Palacio de la Moneda y los altercados en los días sucesivos filmados por Ángel Torti los días 11, 13 y 14 de septiembre de 1973 que forman parte del archivo del museo.

El grueso de la producción del Museo de la Memoria a partir de grabaciones originales se articula en las siguientes series temáticas: Archivo oral, Archivo de la memoria en Chile, Testimonios de la memoria, Serie encuentro y Cien entrevistas ${ }^{32}$.

Más allá de lo específico y relevante de cada una de las piezas y series producidas por el museo, nos interesa una aproximación más general alineada con sus objetivos prioritarios. En primer lugar, con estas producciones propias, el museo hace un esfuerzo por ampliar el relato y descentralizar en ciertos aspectos la memoria hegemónica. Es decir, por situar las violaciones de Derechos Humanos y la militancia en lugares distintos de Santiago, dado que la ciudad se ha erigido como epicentro o

${ }^{32}$ La orientación, contenidos y algunas de las mismas pueden consultarse en la página web del museo (ver https://ww3.museodelamemoria.cl/audiovisuales/) En este caso, solo entre una y tres piezas de cada una de las series están disponibles en el museo virtual a modo ilustrativo, en la web del museo. Sí es posible consultar las series completas en el CEDAV y el CEDOC. 
lugar de confluencia de buena parte de los testimonios e imágenes que constituyen el imaginario sobre la dictadura. También, yendo más allá del golpe de Estado que la propia institución sitúa en el centro de su colección permanente. En este sentido, algunos de los audiovisuales producidos por el museo contribuyen a visibilizar la labor de entidades y asociaciones de carácter no-tan-institucional con el propósito de subrayar la violencia también perpetrada contra colectivos y regiones diversas 33 .

Destaca el trabajo de mediación específico con series como el "Archivo oral". Los testimonios recogidos bajo esta etiqueta varían de los pocos minutos a las varias horas y, si bien es posible consultarlo a través de diferentes vías, el museo también realiza piezas de compilación a partir de estos materiales para hacer más accesible y amable el relato en su conjunto a los visitantes/espectadores. Un ejemplo reciente que da buena cuenta de esta labor es el largometraje UNAC34 / Coordinador Cultural (2019)35, elaborado a partir de los testimonios que conforman el llamado "Archivo Oral Resistencia Cultural en Dictadura". En este caso, los testimonios de los protagonistas se presentan en un montaje alterno en el que se articulan de manera cronológica los diferentes episodios y acontecimientos que relatan, facilitando el acceso del público generalista al tiempo que sintetizando las muchas informaciones recogidas en sus declaraciones $-\mathrm{y}$ que, si bien son de interés para un proyecto de memoria oral como en el que se inscriben, en cierto sentido entorpecen una primera aproximación al tema-. Al mismo tiempo, el Museo de la Memoria aprovecha sus instalaciones para mostrar piezas como esta, convocar al público interesado y provocar el debate entre los asistentes, cumpliendo también así, por estas otras vías, con su objetivo

\footnotetext{
33 La serie "Archivo de la memoria en Chile", que quizá sea la más compleja y de perspectivas más amplias en esta dirección, recoge videos de la investigación (que sigue ampliándose) sobre las violaciones a los Derechos Humanos cometidas en todo el país. En los casos recogidos en formato audiovisual se trata de construir la narración de los acontecimientos, hechos, procesos y detenciones de las cuales los testimoniantes fueron testigos directos. Sus resultados han sido recogidos en varias publicaciones editadas por el Museo (MMDDHH, 2014a; 2014b; 2015; 2016a; 2016b; 2018; 2019d)

34 Unión Nacional por la Cultura (UNAC).

35 El responsable de la pieza es Walter Roblero, coordinador del Archivo Oral.
} 
de involucrar a los ciudadanos en el debate y en su propuesta de memoria colectiva ${ }^{36}$.

\subsection{Las producciones especiales y el museo como escenario}

Otro de los esfuerzos que lleva a cabo el museo, y que de manera especial interesa en este trabajo, es el de conectar el espacio físico de la exposición con el audiovisual de producción propia y con el mundo. Los audiovisuales que siguen generan lazos entre el Museo de la Memoria, la historia, la sociedad, las piezas de la exposición y los relatos de los testimoniantes y los visitantes, que se convierten también en testimonio. Destacan fundamentalmente las series Testimonios de la memoria, donde los protagonistas de la pieza dialogan con alguno de los objetos de la exposición, y Encuentro37. La segunda serie tiene una premisa bien concreta: se trata de videos en los que se presenta el caso de alguien que se ha reconocido en alguna de las imágenes de la colección permanente del museo, o que ha sido reconocido por otra persona, y se acerca al espacio físico de la exposición para establecer un diálogo con esas imágenes "suyas" del pasado. Uno de los casos es el de Eduardo Labarca Goddard: en el video de la serie Encuentro que protagoniza, el periodista y escritor chileno cuenta su relación con las imágenes que alberga una de las estaciones multimedia del museo, en particular con las que muestran a militares quemando libros y que forman parte del reportaje de Klaus Ecksetein Chile, el quiebre, del 28 de septiembre de 1973. Entre los libros que se identifican en las imágenes, está Chile invadido, obra de Labarca Goddard y publicado en 1968. En los 6,13 minutos que dura esta pieza grabada en 2017, el protagonista nos cuenta, desde el interior del museo y junto a la estación multimedia mencionada, cómo fue el hijo de su mujer quien visitó en primer lugar el museo y vio, en esas imágenes, entre otros libros, la cubierta de Chile invadido.

\footnotetext{
${ }^{36}$ En esta ocasión, UNAC / Coordinador Cultural se presentó el 21 de agosto de 2019 en el auditorio / la sala de cine del Museo de la Memoria. Posteriormente se celebró un debate / encuentro con el público en el que participaron Walter Roblero, Virginia Errazuriz, Jorge Olave, Lilia Santos y Antonio Kadima.

37 En el primer caso, no es posible acceder a los videos de la serie en el museo virtual, donde sí está disponible la segunda serie; en todo caso, los materiales se pueden consultar en el CEDAV y CEDOC.
} 
Cabe destacar igualmente uno de los episodios de Declaración, una de las denominadas "Producciones especiales" que ha llevado a cabo el Museo de la Memoria en estos años. La serie Declaración. 20 autores, 20 miradas, 20 historias fue cofinanciada por el Consejo Nacional de Televisión (fondo CNTV). Producida en 2013, la propuesta consistía en invitar a veinte cineastas chilenos en activo a que reflexionaran sobre alguno de los artículos de la Declaración Universal de los Derechos Humanos y elaboraran una pieza audiovisual de varios minutos que dialogara con el artículo de su elección. Entre los cineastas participantes están Carmen Luz Parot, Sebastián Lelio, Alicia Scherson, Ignacio Agüero o Maite Alberdi.

También el espacio físico del Museo de la Memoria es protagonista en una de estas piezas: en Museo (2,25 minutos) ${ }^{38}$, dirigida por Nicolás Acuña y dedicada al artículo 26 de la Declaración Universal de Derechos Humanos: "Toda persona tiene derecho a la educación. La instrucción elemental será obligatoria". En el cortometraje, una niña recorre el Museo de la Memoria, una limpiadora también, coinciden frente a uno de los paneles explicativos que hay en el museo y la niña le dice "¿quieres que te lo lea?" Y procede. Luego le pide el teléfono a la mujer, que es su madre, lo toma y se va; la madre queda sonriendo frente al cartel. Con la sencilla narrativa, queda evidenciado y subrayado el propósito educativo del museo y su mediación en la configuración de memorias y la transmisión de la que, en concreto, él propone39.

\section{Ideas finales}

Tanto el recorrido propuesto en estas páginas como el acercamiento real a los diferentes sitios e iniciativas de memoria desarrolladas al abrigo de la política estatal en Chile ponen de manifiesto el peso que tienen el audiovisual y el testimonio en el Museo de la Memoria y los Derechos Humanos. El que se trate de un edificio de nueva construcción y de un espacio no significado en términos memorísticos con anterioridad también marca una diferencia con

\footnotetext{
${ }^{8}$ Ver video: https://www.youtube.com/watch?v=W7_GXuLooTk

39 Las series "Declaración" y "Encuentro" están completas y accesibles en el museo virtual y los otros espacios de consulta de materiales digitales.
} 
respecto a otros sitios de memoria del país y quizá sea uno de los motivos que ha facilitado poner el acento de la colección permanente y diseño museográfico general en lo audiovisual. Señalamos también arriba el esfuerzo de la institución por trascender sus muros y llevar más lejos la memoria colectiva que propone a través del museo virtual y, por supuesto, a través de las imágenes que produce y que muchas veces difunde por este mismo canal.

Más allá de sus tareas de archivo y de la exhibición y difusión de materiales audiovisuales ajenos y de producción propia en el museo físico, en sus actividades paralelas y en el museo virtual, el CEDOC tiene un marcado perfil de intermediador y facilitador en la gestión de imágenes y documentos sobre la dictadura. Además de facilitar el acceso y visionado a materiales específicos, el Museo de la Memoria orienta y ayuda en la gestión de derechos a cineastas y creadores que quieran trabajar a partir de materiales incluidos en su archivo. Algo que lo convierte también en un cómplice de la elaboración y desarrollo de relatos y discursos diferentes al que propone el propio Museo de la Memoria.

Es muy interesante el modo en que, como hemos señalado, el museo ciñe el discurso de su colección permanente al periodo 1973-1990, pero lo abre infinitamente a través de las exposiciones temporales y actividades paralelas que organiza a lo largo de todo el año, estrechando también los vínculos de la memoria de la dictadura chilena con el campo más amplio de los Derechos Humanos en el contexto mundial y en el presente. En todo caso, en el trabajo constante de pensarse a sí mismo, es posible (y deseable) que en algún momento el museo incorpore los propios debates y discusiones de los que está siendo protagonista a su discurso central, poniendo el acento en las complejidades y las tensiones existentes entre las memorias individuales, las colectivas y las públicas. Echamos también en falta una atención más significativa a las disonancias existentes entre los diferentes relatos en circulación, al margen de su carácter más oficial o más independiente, y a las particularidades de los sitios, monumentos y memoriales que, aunque estén presentes tímidamente en el museo (en la planta baja, como preámbulo a la colección permanente), recorren Chile. 
Para terminar, y en relación también a sus estrictos límites y su capacidad para atravesarlos con exposiciones temporales y otras actividades, vale la pena señalar el papel que el Museo de la Memoria ha asumido en relación a los últimos acontecimientos socio-políticos en Chile y con respecto a las vulneraciones de los Derechos Humanos cometidas durante las acciones de control y represión de las movilizaciones que se vienen sucediendo en el país desde el 18 de octubre de 2019. Podemos decir que el museo ya ha incorporado el caso a su relato a través de acciones como los talleres "Antes del olvido. Memoria y registro tridimensional", organizados en colaboración con Metashape y cuyo objetivo es tomar registros tridimensionales del espacio urbano para conservar el efecto que ha tenido sobre la ciudad la "Primavera chilena de 2019" para más tarde mostrarlos en sesiones celebradas en el museo. Lejos de ayudar a clausurarlo, seguramente acciones como la descrita aviven aún más el debate y añadan frentes y diálogos a las discusiones abiertas en torno al Museo de la Memoria.

\section{Referencias bibliográficas}

Aguilera, C. (2015). Víctimas y mártires de la violencia política reciente en chile. ¿Una memoria pública en disputa?, AUS [Arquitectura / $\begin{array}{lllll}\text { Urbanismo } & \text { / Sustentabilidad], } & \mathrm{n}^{\mathrm{O}} & 20, & 12-19 .\end{array}$ http://revistas.uach.cl/index.php/aus/article/view/4

Aguilera, C. (2013). Londres 38 y Patio 29: vacíos llenos de recuerdos. La configuración de espacios de memoria a 40 años del golpe militar en Chile, Revista de Geografía Espacios, vol. 3, nº6, 98-116.

Aguilera, C. y Cáceres, G. (2012). Signs of State Terrorism in PostAuthoritarian Santiago: Memories and Memorialization in Chile, Hispanic Journal of Theory and Criticism, vol. 4, n ${ }^{0} 8$, pp. 1-16.

Alonso Fernández, L. (1999 [2012]). Nueva museología. Planteamientos y retos para el futuro. Madrid: Alianza Editorial [Segunda edición revisada y actualizada por Isabel García Fernández].

Campos, M. (2017). Audiovisuales en el Museo Arqueológico Nacional: estrategias expositivas y educativas. Tarbiya: Revista de investigación $e$ innovación educativa, $\mathrm{n}^{\circ} 45,23-38$. Consulta online: https://revistas.uam.es/tarbiya/article/view/9506

Campos Pérez, M. (2015). Construcciones visuales y memorias de la dictadura de Pinochet a través de películas y reportajes extranjeros (1973-2013). Amnis. Revue d'études des sociétés et cultures 
contemporaines Europe-Amérique, $\quad \mathrm{n}^{\mathrm{o}} \quad 14, \quad \mathrm{pp}$ https://journals.openedition.org/amnis/2645

Jelin, E. (2002 [2001]). Los trabajos de la memoria. Madrid: Siglo XXI.

Jelin, E. (2005). Exclusión, memorias y luchas políticas. En Daniel Mato (ed.), Cultura, política y sociedad. Perspectivas latinoamericanas (pp. 219-239). Buenos Aires: Consejo Latinoamericano de Ciencias Sociales, http://bibliotecavirtual.clacso.org.ar/ar/libros/grupos/mato/Jelin.rtf

Jelin, E. (2009). ¿Quiénes? ¿Cuándo? ¿Para qué? Actores y escenarios de las memorias. En Ricard Vinyes (ed.) El estado y la memoria. Gobiernos $y$ ciudadanos frente a los traumas de la historia (pp. 117-150). Barcelona, RBA, 2009.

Jelin, E. (2014). Memoria y democracia. Una relación incierta, Revista Mexicana de Ciencias Políticas y Sociales, año LIX, $\mathrm{n}^{0}$ 221, mayoagosto, pp. 225-242.

Lagos, P. S. (2017). Videoactivismo, denuncia y (contra)memorias. Archivos de la Filmoteca, $\mathrm{n}^{0}$ 73, 139-155.

Lira, E. (2009). Las resistencias de la memoria. Olvidos jurídicos y memorias sociales. En Ricard Vinyes (ed.) El estado y la memoria. Gobiernos y ciudadanos frente a los traumas de la historia (pp. 67-116). Barcelona: RBA.

Ministerio de Bienes Nacionales (2015). Ruta de la Memoria. Santiago. 1973-1989. content/uploads/2015/01/48.pdf

http://rutas.bienes.cl/wp-

Huyssen, A. (2002). En busca del futuro perdido. Cultura y memoria en tiempos de globalización. México D. F.: Fondo de Cultura Económica.

Huyssen, A. (2009). Prólogo. En Claudia Feld y Jessica Stites Mor (comp.), El pasado que miramos. Memoria e imagen ante la historia reciente (pp. 15-24), Barcelona: Paidós.

Huyssen, A. (2011). International Human Rights and the Politics of Memory: Limits and Challenges. Criticisim, vol. 53, $\mathrm{n}^{\circ} 4,607-624$.

Iáñez Ortega, M. (2014). Musealización del patrimonio cinematográfico. Los museos de cine. Bellido Gant, M. L. (ed.) Arte y museos del siglo XXI. Entre los nuevos ámbitos y las inserciones tecnológicas (pp. 37-52). Barcelona: Editorial UOC.

Palacios, J. M. y Donoso, C. (2017). Infancia y exilio en el cine chileno. Iberoamericana, XVII, $\mathrm{n}^{0} 65,45^{-66}$.

Richard, N. (2002). La crítica de la memoria. Cuadernos de Literatura, Bogotá (Colombia), no 8 (15): 8, enero-junio, 187-193.

Sarlo, B. (2005). Tiempo pasado. Cultura de la memoria y giro subjetivo. Una discusión. Buenos Aires: Siglo XXI

Serrano Madrid, V. (2010). Proyecto arquitectónico. Museo de la Memoria y los Derechos Humanos [publicación sobre el proyecto]. Santiago: 
MMDDHH

https://ww3.museodelamemoria.cl/wpcontent/files_mf/1563900982LIBROMMDHMOP web.pdf

Smith Bautista, S. y Balsamo, A. (2013 [2016]). Understanding the Distributed Museum: Mapping the Spaces of Museology in Contemporary Culture. Boddington, A., Boys, J. y Speight, C. (eds.) Museums and Higher Education Working Together. Challenges and Opportunities (pp. 55-70). Abington y Nueva York: Routledge.

Wolff Rojas, T. (2016). Pensamientos sobre la representación de la memoria traumática en el Museo de la Memoria y los Derechos Humanos (MMDH), Santiago de Chile, Intervención, año $7, \mathrm{n}^{0} 13$, enero-junio, 61-73.

\section{Fuentes (materiales y publicaciones del museo)}

MMDDHH, (2019a). Sobre el museo.

https://ww3.museodelamemoria.cl/sobre-el-museo/ [acceso: 01/08/2019]

MMDDHH, (2019b). "Víctimas", Interactivos. https://interactivos.museodelamemoria.cl/victimas/ [acceso: 05/08/2019]

MMDDHH, (2019c). "Justicia", Interactivos. https://interactivos.museodelamemoria.cl/justicia/ [acceso: 05/08/2019]

MMDDHH, (2019d). Archivo de la memoria en Chile. Investigación, catastro y recopilación de patrimonio tangible e intangible sobre los derechos humanos en la región Magallanes. Santiago de Chile: Museo de la Memoria y los Derechos Humanos.

https://ww3.museodelamemoria.cl/wpcontent/files_mf/1562862669Archivosmemoriachile_magallanes.pdf [consulta: 07/08/2019]

MMDDHH, (2018). Archivo de la memoria en Chile. Región del Libertador O'Higgins. Santiago de Chile: Museo de la Memoria y los Derechos Humanos.

https://ww3.museodelamemoria.cl/publicaciones/archivos-de-lamemoria-en-chile-ohiggins/ [consulta: 07/08/2019]

MMDDHH, (2016a). Archivo de la memoria en Chile. Región del Bio Bío. Santiago de Chile: Museo de la Memoria y los Derechos Humanos. https://ww3.museodelamemoria.cl/publicaciones/archivos-de-lamemoria-de-chile-bio-bio/ [consulta: 07/08/2019]

MMDDHH, (2016b). Archivo de la memoria en Chile. Región de la Araucanía. Santiago de Chile: Museo de la Memoria y los Derechos Humanos.

https://ww3.museodelamemoria.cl/publicaciones/archivos-de-lamemoria-de-chile-araucania/ [consulta: 07/08/2019] 
MMDDHH, (2015). Archivo de la memoria en Chile. Región de Antofagasta. Santiago de Chile: Museo de la Memoria y los Derechos Humanos. https://ww3.museodelamemoria.cl/publicaciones/archivos-de-lamemoria-de-chile-antofagasta/ [consulta: 07/08/2019]

MMDDHH, (2014a). Archivo de la memoria en Chile. Región de Coquimbo. Santiago de Chile: Museo de la Memoria y los Derechos Humanos. https://ww3.museodelamemoria.cl/publicaciones/archivos-de-lamemoria-de-chile-coquimbo/ [consulta: 07/o8/2019]

MMDDHH, (2014b). Archivo de la memoria en Chile. Región de los Ríos y de los Lagos. Santiago de Chile: Museo de la Memoria y los Derechos Humanos. https://ww3.museodelamemoria.cl/publicaciones/archivos-de-lamemoria-de-chile-los-rios-y-los-lagos/ [consulta: 07/o8/2019]

MMDDHH, (2013). Material educativo autoguiado. Museo de la Memoria y los Derchos Humanos. https://ww3.museodelamemoria.cl/publicaciones/autoguiado/ [consulta: 07/08/2019]

MMDDHH, (2010). Museo de la Memoria y los Derechos Humanos. [publicación sobre el proyecto arquitectónico] https://ww3.museodelamemoria.cl/wpcontent/files_mf/1563900982LIBROMMDHMOP_web.pdf [consulta: 19/01/2020]

\section{Entrevistas}

María Luisa Ortiz. Jefa del área de Colecciones e investigación. Museo de la Memoria y los Derechos Humanos. Santiago de Chile. 23 de julio de 2019.

José Manuel Rodríguez Leal. Responsable del archivo audiovisual. Museo de la Memoria y los Derechos Humanos. Santiago de Chile. 13 de agosto de 2019.

Claudia Videla Sotomayor. Encargada de contenidos. Departamento de Educación y Audiencias. Museo de la Memoria y los Derechos Humanos. Santiago de Chile. 21 de agosto de 2019. 